\title{
Initial Assessment of Alternate Metals in Chalcogels
}

Fuel Cycle Research \& Development

Prepared for

U.S. Department of Energy B.J. Riley, W.C. Lepry, J. Chun, and D.M. Strachan Pacific Northwest National Laboratory June 29, 2012 FCRD-SWF-2012-000136 PNNL-21488 


\section{DISCLAIMER}

This information was prepared as an account of work sponsored by an agency of the U.S. Government. Neither the U.S. Government nor any agency thereof, nor any of their employees, makes any warranty, expressed or implied, or assumes any legal liability or responsibility for the accuracy, completeness, or usefulness, of any information, apparatus, product, or process disclosed, or represents that its use would not infringe privately owned rights. References herein to any specific commercial product, process, or service by trade name, trade mark, manufacturer, or otherwise, does not necessarily constitute or imply its endorsement, recommendation, or favoring by the U.S. Government or any agency thereof. The views and opinions of authors expressed herein do not necessarily state or reflect those of the U.S. Government or any agency thereof. 


\section{SUMMARY}

This report provides an up-to-date account of the non-Pt based chemistries available in the literature for making non-oxide, chalcogen-based aerogels, called chalcogels, for the potential application of iodine capture (Table S.1). In each case, a combination of multiple precursors is required to make the chalcogels and, in most cases, the precursors are not currently commercially available and must be prepared in the laboratory. References for the preparation details of these precursors have been provided for each. An account of the chalcogels made at Pacific Northwest National Laboratory (PNNL) is also given in this report along with iodine sorption efficiencies for three very diverse chalcogel chemistries. A brief account of consolidation options is provided.

Table S.1. Summary of non-Pt chalcogel chemistries (families). " $M$ " denotes an interlinking metal (see text).

\begin{tabular}{ll}
\hline Chemistry (Family) & Reference \\
\hline (Cd,Zn,Pb)-(S,Se) & (Mohanan et al., 2005) \\
\hline Ge-S & (Kalebaila et al., 2006) \\
\hline (Mo,W)-M-S & (Bag et al., 2009) \\
\hline (Sn,Sb)-M-(S,Se) & (Bag and Kanatzidis, 2010) \\
\hline Zn-Sn-S & (Oh et al., 2011) \\
\hline Fe-Sn-S & (Yuhas et al., 2011b) \\
\hline Fe-M-Sn-S & (Yuhas et al., 2011a) \\
\hline Mo-Co-M-S & (Polychronopoulou et al., 2012) \\
\hline
\end{tabular}




\section{CONTENTS}

SUMMARY iii

ABBREVIATIONS AND DEFINITIONS $\mathrm{V}$

1 INTRODUCTION 1

2 OVERVIEW OF CHALCOGEL FABRICATION METHODS 3

3 OVERVIEW OF CHALCOGEL ADSORPTION POTENTIAL ….......................................... 5

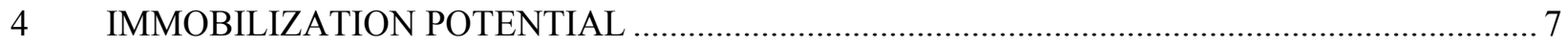

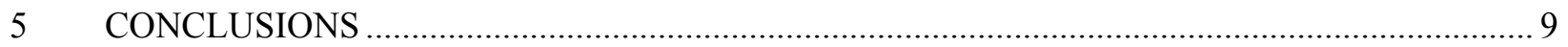

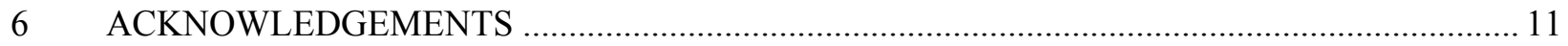

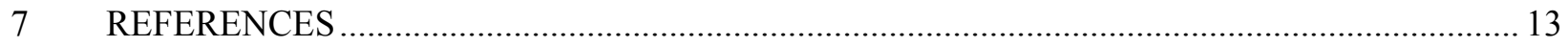

APPENDIX A: COMPILATION OF SELECTED CHALCOGEL DATA FROM LITERATURE ....... A.1

\section{FIGURES}

Figure 1. Schematic showing a chalcogel network of tetrahedrally-bound $\mathrm{Ge}_{4} \mathrm{~S}_{10}{ }^{4-}$ clusters with an interlinking metal, e.g., $\mathrm{Pt}^{2+}$ 1

Figure 2. Summary collages of how PNNL chalcogels were fabricated. 4

Figure 3. SEM micrograph of Sn-S chalcogel (left) and nitrogen adsorption/desorption isotherms of a Pt-Ge-S chalcogel (right)..

Figure 4. Schematic diagram of the experimental setup for iodine uptake test in breathing air containing $\mathrm{I}_{2}(\mathrm{~g})$ at $4.2 \mathrm{ppm}$ (left) and a photograph of a Pt-Ge-S chalcogel in the tip of the pipette used as the column prior to an experiment (right) (Strachan et al., 2011).

Figure 5. Gaseous iodine adsorption potential of various chalcogel chemistries.

Figure 6. Glass formation tendency in Sn-Ge-S chalcogenide glasses (Ruffolo and Boolchand, 1985).

\section{TABLES}

Table 1. Summary of non-Pt chalcogel chemistries (families) ............................................................ 2

Table 2. A list of chalcogenido clusters that have been used to make chalcogels................................... 3

Table A.1. Summary of chalcogel data in the literature ...................................................................... A.3 


\section{ABBREVIATIONS AND DEFINITIONS}

AN aggregation of nanocrystals/nanoparticles (chalcogel fabrication method)

BET Brunauer-Emmett-Teller method for measuring specific surface area of a material

CL chemical linkage of clusters (chalcogel fabrication method)

DF decontamination factor

ICP inductively coupled plasma

$M \quad$ interlinking metal (used in CL method for chalcogel fabrication)

MS mass spectrometry

mw molecular weight $(\mathrm{g} / \mathrm{mole})$

PNNL Pacific Northwest National Laboratory

ppm parts per million (by volume)

TMA tetramethyl ammonium

TEA tetraethyl ammonium

XRD X-ray diffraction

XRF X-ray fluorescence 



\section{INTRODUCTION}

A new family of non-oxide, chalcogen-based aerogels, called chalcogels, has been reported in the literature (Mohanan et al., 2005; Kalebaila et al., 2006; Bag et al., 2007; Kanatzidis and Bag, 2008; Bag et al., 2009; Bag and Kanatzidis, 2010; Oh et al., 2011; Yuhas et al., 2011b; Yuhas et al., 2011a; ShafaeiFallah et al., 2011; Riley et al., 2011; Polychronopoulou et al., 2012). These chalcogels, because of their potential high affinity for halide gases and their high porosity, were thought to be ideal candidates for removal of ${ }^{129} \mathrm{I}$ from the process gases at a nuclear fuel reprocessing plant. Initially, platinum $(\mathrm{Pt})$ was used in making these chalcogels and, as such, would be inappropriate for use as a sorbent in an operating plant because of the cost of Pt. Therefore, we began to investigate not only the sorption properties of these chalcogels, but the replacement of $\mathrm{Pt}$ in the structure with other, more practical metals.

Some of the first chalcogels reported in the literature were made from an aggregation of simple binary nanocrystals such as $\mathrm{CdS}, \mathrm{ZnS}, \mathrm{PbS}$, etc., however, this fabrication route (aggregation of nanocrystals or AN method) was limited to the available chemistries of nanocrystals or nanoparticles (Mohanan et al., 2005) (Table 1). After work on these chalcogels was published, a more compositionally flexible chalcogel synthesis route was discovered by the Kanatzidis Group at Northwestern University. In these chalcogels, a porous network was formed by a chemical linkage between chalcogenido clusters (e.g., $\mathrm{Sn}_{2} \mathrm{~S}_{6}{ }^{4-}$ ) and metal ions (e.g., $\mathrm{Sn}^{2+}$ ) that promoted interlinking of the structural units (chemical linkage or CL method, Table 1), where the main structural units were composed of $\mathrm{Ge}-(\mathrm{S}, \mathrm{Se})$ and the interlinking metal was $\mathrm{Pt}^{2+}$ (Figure 1) (Bag et al., 2007; Kanatzidis and Bag, 2008). After that work and some subsequent work, it was determined that it is very difficult to make Ge-based chalcogels by this processing route without $\mathrm{Pt}^{2+}$ as the interlinking metal, e.g., $\mathrm{Ge}-(\mathrm{Sb}, \mathrm{Pt})-\mathrm{Se}$ (Bag and Kanatzidis, 2010). Thus, alternative cluster building blocks were investigated including $\mathrm{SnS}_{4}{ }^{4-}, \mathrm{Sn}_{2} \mathrm{~S}_{6}{ }^{4-}, \mathrm{Sn}_{4} \mathrm{~S}_{10}{ }^{4-}, \mathrm{SbSe}_{4}{ }^{3-}$, $\mathrm{MoS}_{4}{ }^{2-}$, and $\mathrm{WS}_{4}{ }^{2-}$.

The primary goal of this report is to define the various options available for making chalcogels for ${ }^{129} \mathrm{I}$ capture and immobilization that do not contain Pt. A summary of the wide compositional flexibility of chalcogel chemistries based on non-Pt interlinking metals is provided in Table 1. All of the work discussed hereafter is based on this second fabrication technique (CL method).

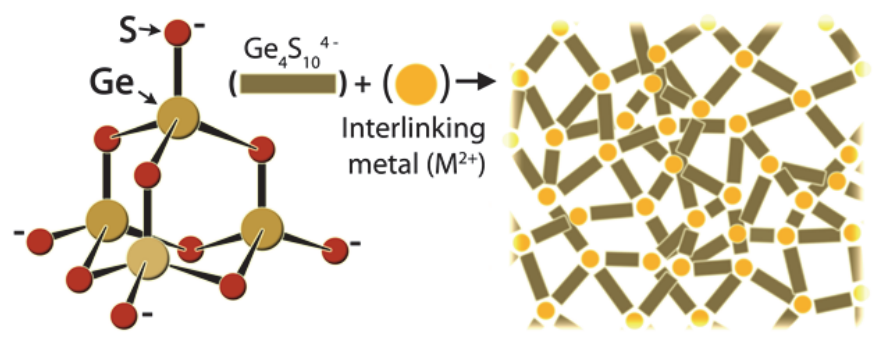

Figure 1. Schematic showing a chalcogel network of tetrahedrally-bound $\mathrm{Ge}_{4} \mathrm{~S}_{10}{ }^{4-}$ clusters with an interlinking metal, e.g., $\mathrm{Pt}^{2+}$.

An overview of the precursor ions and key results from the available literature for chalcogels made with the CL fabrication method are presented in Appendix A. From Appendix A, it is apparent that the different compositions require different aging times and have different surface areas. 
Table 1. Summary of non-Pt chalcogel chemistries (families). *AN: aggregation of nanocrystals; CL: chemical linkage of clusters.

\begin{tabular}{|c|c|c|c|c|}
\hline Chemistry (Family) & Method* & $\begin{array}{l}\text { Chalcogenido } \\
\text { cluster(s) }\end{array}$ & $\begin{array}{l}\text { Interlinking } \\
\text { metal(s), } M\end{array}$ & Reference(s) \\
\hline$(\mathrm{Cd}, \mathrm{Zn}, \mathrm{Pb})-(\mathrm{S}, \mathrm{Se})$ & AN & $\mathrm{N} / \mathrm{A}$ & N/A & (Mohanan et al., 2005) \\
\hline Ge-S & $\mathrm{AN}$ & $\mathrm{N} / \mathrm{A}$ & $\mathrm{N} / \mathrm{A}$ & (Kalebaila et al., 2006) \\
\hline$(\mathrm{Mo}, \mathrm{W})-M-\mathrm{S}$ & $\mathrm{CL}$ & $(\mathrm{Mo}, \mathrm{W}) \mathrm{S}_{4}{ }^{2-}$ & $\mathrm{Co}^{2+}, \mathrm{Ni}^{2+}$ & $\begin{array}{l}\text { (Bag et al., 2009; } \\
\text { Shafaei-Fallah et al., } \\
\text { 2011) }\end{array}$ \\
\hline$(\mathrm{Sn}, \mathrm{Sb})-M-(\mathrm{S}, \mathrm{Se})$ & $\mathrm{CL}$ & $\begin{array}{l}\mathrm{Sn}_{2}(\mathrm{~S}, \mathrm{Se})_{6}^{4-} \\
\mathrm{Sn}(\mathrm{S}, \mathrm{Se})_{4}^{4-}, \mathrm{SbSe}_{4}{ }^{3-}\end{array}$ & $\mathrm{Sn}^{2+}, \mathrm{Sb}^{3+}$ & $\begin{array}{l}\text { (Bag and Kanatzidis, } \\
2010)\end{array}$ \\
\hline $\mathrm{Zn}-\mathrm{Sn}-\mathrm{S}$ & $\mathrm{CL}$ & $\begin{array}{l}\mathrm{SnS}_{4}^{4-}, \mathrm{Sn}_{2} \mathrm{~S}_{6}^{4-} \\
\mathrm{Sn}_{4} \mathrm{~S}_{10}{ }_{4-}\end{array}$ & $\mathrm{Zn}^{2+}$ & (Oh et al., 2011) \\
\hline Fe-Sn-S & $\mathrm{CL}$ & $\mathrm{Fe}_{4} \mathrm{~S}_{4}{ }^{m-}, \mathrm{Sn}_{2} \mathrm{~S}_{6}{ }^{4-}$ & $\mathrm{Fe}_{4} \mathrm{~S}_{4}{ }^{m-}, \mathrm{Sn}_{2} \mathrm{~S}_{6}{ }^{4-}$ & (Yuhas et al., 2011b) \\
\hline Fe- $M-\mathrm{Sn}-\mathrm{S}$ & $\mathrm{CL}$ & $\mathrm{Fe}_{4} \mathrm{~S}_{4}{ }^{m-}, \mathrm{Sn}_{2} \mathrm{~S}_{6}{ }^{4-}$ & $\begin{array}{l}\mathrm{Zn}^{2+}, \mathrm{Sn}^{2+}, \mathrm{Ni}^{2+}, \\
\mathrm{Co}^{2+}\end{array}$ & (Yuhas et al., 2011a) \\
\hline Mo-Co-M-S & $\mathrm{CL}$ & $\mathrm{MoS}_{4}^{2-}$ & $\begin{array}{l}\mathrm{Co}^{2+}, \mathrm{Pb}^{2+}, \mathrm{Cd}^{2+}, \\
\mathrm{Pd}^{2+}, \mathrm{Cr}^{3+}, \mathrm{Bi}^{3+}\end{array}$ & $\begin{array}{l}\text { (Polychronopoulou et } \\
\text { al., 2012) }\end{array}$ \\
\hline
\end{tabular}




\section{OVERVIEW OF CHALCOGEL FABRICATION METHODS}

The typical fabrication route for making chalcogels with the CL method involves dissolving the individual precursors in separate solutions in a particular solvent, combining the solutions, and allowing gelation to occur, in which the clusters and interlinking metal(s) form an interconnected, porous network. For each chemical system, the precursors, the solvent, the precursor concentrations in the solvent, the gelation time, and the resultant chalcogel properties differ. The most commonly used solvents for dissolving the precursors are water, formamide, and $N, N$-dimethylformamide. Most of the chalcogenide clusters are not commercially available, and thus require fabrication in the laboratory, typically through wet chemical or hydrothermal (in an autoclave) synthesis routes. A list of the common chalcogenido cluster ions used as chalcogel precursors is provided in Table 2 along with references for the fabrication methods. The comprehensive list of non-Pt metal interlinking ions reported in the literature is found in Table 1. These precursors can potentially be used to make chalcogels.

At Pacific Northwest National Laboratory (PNNL), we have made Pt-Ge-S ( $\left.\mathrm{PtGe}_{2} \mathrm{~S}_{5}\right)$, Mo-Co-Ni-S $\left(\mathrm{Mo}_{2} \mathrm{CoNiS}_{8}\right)$, and $\mathrm{Sn}-\mathrm{S}\left(\mathrm{Sn}_{2} \mathrm{~S}_{3}\right)$ chalcogels and the summary collages of methods are presented in Figure 2 (Ryan et al., 2009; Strachan et al., 2010; Strachan et al., 2011; Riley et al., 2011). We evaluated two casting techniques in which we cast the mixed precursors in either polymer vials or petri dishes. Based on the volume reduction and drastic color changes, the gels cast in a petri dish seemed to dehydrate and oxidize, respectively. Therefore, we cast them exclusively in polymer vials to avoid the deleterious dehydration and oxidation (Ryan et al., 2009; Strachan et al., 2010). After allowing the solutions to undergo gelation (2-4 wks), the gels were removed from the vials, cut into 3-6 mm granules, rinsed with water and ethanol, solvent exchanged completely to ethanol, and then solvent exchanged in liquid $\mathrm{CO}_{2}$ within an autoclave. The $\mathrm{CO}_{2}$ was taken supercritical by heating (supercritical drying) and vented as gas to preserve the pore structure of the gels. Examination of the supercritically dried chalcogels in a scanning electron microscope (SEM) revealed highly porous microstructures that were confirmed to have high specific surface areas as measured with nitrogen adsorption/desorption isotherms (Figure 3). We have also investigated making xerogels in which the gel was not supercritically dried, but the solvent was allowed to evaporate, collapsing the pore structure.

Table 2. A list of chalcogenido clusters that have been used to make chalcogels. Note that only $\left(\mathrm{NH}_{4}\right)_{2} \mathrm{MoS}_{4}$ and $\left(\mathrm{NH}_{4}\right)_{2} \mathrm{WS}_{4}$ salts are commercially available. ${ }^{*}$ Salt: $\mathrm{Ph}_{4} \mathrm{P}=$ tetrapheny1phosphonium, TMA $=$ tetramethyl ammonium, TEA = tetraethyl ammonium.

\begin{tabular}{lll}
\hline Cluster & Salt* & Reference \\
\hline $\mathrm{Fe}_{4} \mathrm{~S}_{4} \mathrm{Cl}_{4}{ }^{2-}$ & $\left(\mathrm{Ph}_{4} \mathrm{P}\right)_{2}\left(\mathrm{Fe}_{4} \mathrm{~S}_{4} \mathrm{Cl}_{4}\right)$ & (Coucouvanis et al., 1982) \\
\hline $\mathrm{Ge}_{4} \mathrm{~S}_{10}{ }^{4-}$ & $(\mathrm{TMA})_{4} \mathrm{Ge}_{4} \mathrm{~S}_{10}$ & (Bowes et al., 1996) \\
\hline $\mathrm{Ge}_{4} \mathrm{Se}_{10}{ }^{4-}$ & $(\mathrm{TMA})_{4} \mathrm{Ge}_{4} \mathrm{Se}_{10}$ & (Ahari et al., 1998) \\
\hline $\mathrm{MoS}_{4}{ }^{2-}$ & $\left(\mathrm{NH}_{4}\right)_{2} \mathrm{MoS}_{4}$ & (Polychronopoulou et al., 2012) \\
\hline $\mathrm{SnS}_{4}{ }^{4-}$ & $\mathrm{Na}_{4} \mathrm{SnS}_{4}-14 \mathrm{H}_{2} \mathrm{O}$ & (Schiwy et al., 1973) \\
\hline $\mathrm{SnSe}_{4}{ }^{4-}$ & $\mathrm{K}_{4} \mathrm{SnSe}_{4}$ & (Klepp, 1992) \\
\hline $\mathrm{Sn}_{2} \mathrm{~S}_{6}{ }^{4-}$ & $\mathrm{Na}_{4} \mathrm{Sn}_{2} \mathrm{~S}_{6}-14 \mathrm{H}_{2} \mathrm{O}$ & (Krebs et al., 1972) \\
\hline $\mathrm{Sn}_{2} \mathrm{Se}_{6}{ }^{4-}$ & $\mathrm{K}_{4} \mathrm{Sn}_{2} \mathrm{Se}_{6}$ & (Eisenmann and Hansa, 1993) \\
\hline $\mathrm{Sn}_{4} \mathrm{~S}_{10}{ }^{4-}$ & $(\mathrm{TMA})_{4} \mathrm{Sn}_{4} \mathrm{~S}_{10}$ & (Tsamourtzi et al., 2008) \\
\hline $\mathrm{Sn}_{4} \mathrm{Se}_{10}{ }^{4-}$ & $(\mathrm{TEA})_{4} \mathrm{Sn}_{4} \mathrm{Se}_{10}$ & (Tsamourtzi et al., 2008) \\
\hline $\mathrm{SbSe}_{4}{ }^{3-}$ & $\mathrm{K}_{3} \mathrm{SbSe}_{4}$ & (Eisenmann and Zagler, 1989) \\
\hline $\mathrm{WS}_{4}{ }^{2-}$ & $\left(\mathrm{NH}_{4}\right)_{2} \mathrm{WS}_{4}$ & (McDonald et al., 1983) \\
\hline
\end{tabular}




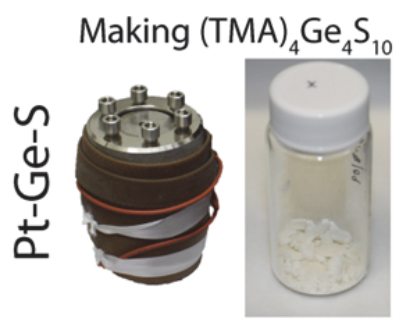

Mixing Precursors
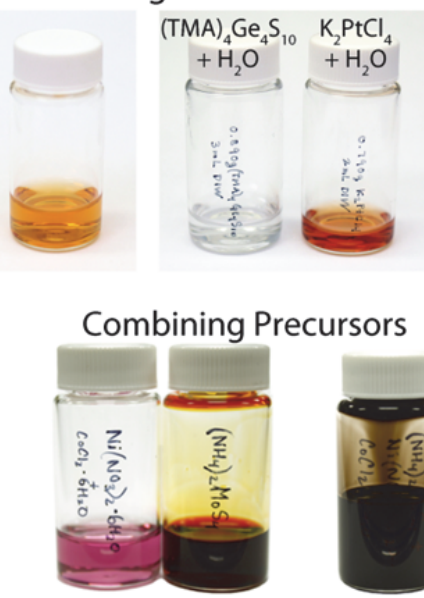

Making Chalcogel
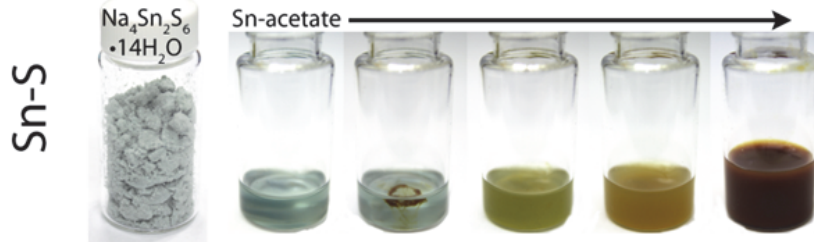

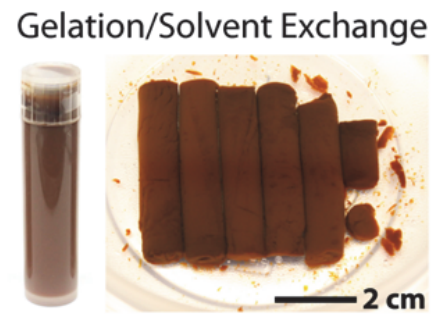

Aerogel
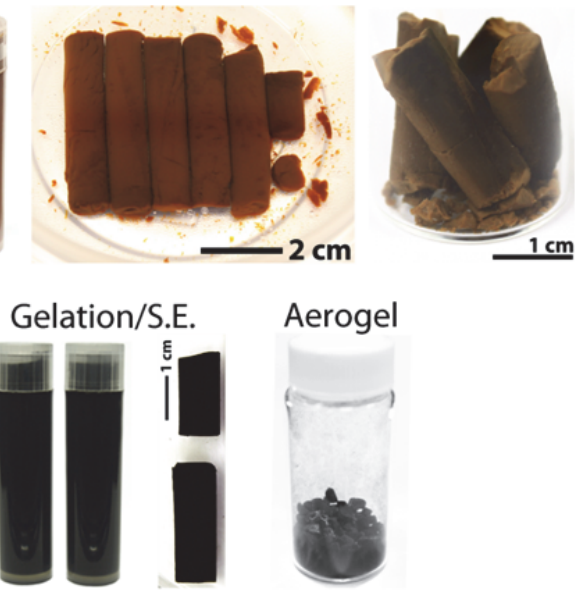

Solvent Exchange

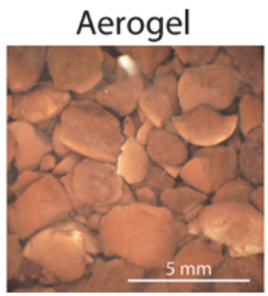

Figure 2. Summary collages of how PNNL chalcogels were fabricated. The targetted compositions for the Pt-Ge-S, Mo-Co-Ni-S, and Sn-S chalcogels were $\mathrm{PtGe}_{2} \mathrm{~S}_{5}, \mathrm{Mo}_{2} \mathrm{CoNiS}_{8}$, and $\mathrm{Sn}_{2} \mathrm{~S}_{3}$, respectively.
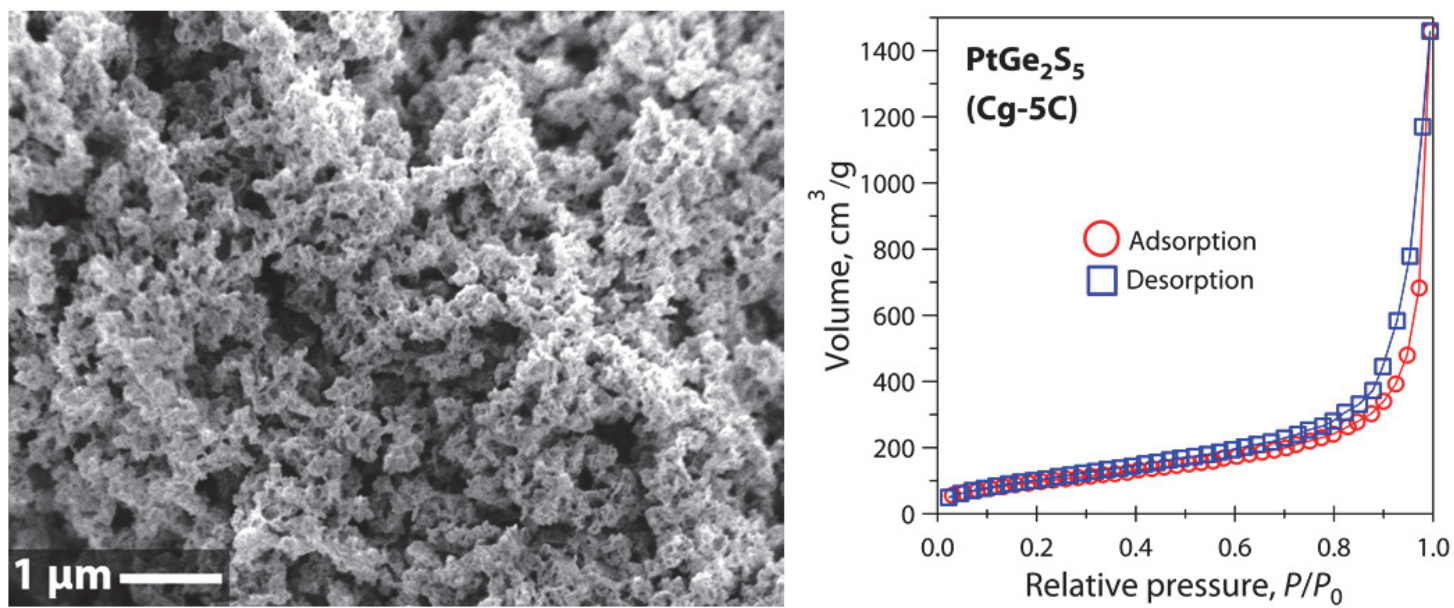

Figure 3. SEM micrograph of Sn-S chalcogel (left) and nitrogen adsorption/desorption isotherms of a PtGe-S chalcogel (right). 


\section{OVERVIEW OF CHALCOGEL ADSORPTION POTENTIAL}

The different chalcogel chemistries made at Northwestern University and PNNL have very different properties, including specific surface areas, gas adsorption potentials, and selective gas adsorption properties. The first selective adsorption potential in chalcogels was presented by the Northwestern University group in 2007 with heavy-metal selectivity, i.e., $\mathrm{Hg}^{2+}$ preferentially over $\mathrm{Zn}^{2+}$, followed by additional work in 2011 with $\mathrm{Zn}-\mathrm{Sn}-\mathrm{S}$ chalcogels in which ionic adsorption of $\mathrm{Pb}^{2+}, \mathrm{Cd}^{2+}, \mathrm{Cu}^{2+}, \mathrm{Cu}^{2+}$, and $\mathrm{Fe}^{2+}$ was measured (Bag et al., 2007; Oh et al., 2011).

Since then, the Northwestern University group has worked on selective gaseous adsorption potential with these chalcogel materials for gaseous separations (Bag et al., 2009; Bag and Kanatzidis, 2010; ShafaeiFallah et al., 2011; Polychronopoulou et al., 2012). In this work, the highly efficient separation of gaseous species with these chalcogels was attributed to the polarizability differences between the different molecules of interest, e.g., $\mathrm{C}_{2} \mathrm{H}_{6}, \mathrm{CO}_{2}, \mathrm{CH}_{4}$, and $\mathrm{H}_{2}$, where more polarizable molecules $\left(\mathrm{C}_{2} \mathrm{H}_{6}\right.$ and $\left.\mathrm{CO}_{2}\right)$ show a stronger attraction to the highly polarizable sulfidic surfaces through dispersion forces than the less polarizable molecules $\left(\mathrm{CH}_{4}\right.$ and $\left.\mathrm{H}_{2}\right)$. For the current work, it is worth noting that $\mathrm{I}_{2}$ gas is also very polarizable.

At PNNL, we started by making Pt-Ge-S chalcogels, the easiest of the known chalcogel materials to fabricate at the time (Ryan et al., 2009). Once made, the maximum $I_{2}$ adsorption potential was evaluated by placing different Pt-Ge-S chalcogels in a vacuum desiccator with iodine crystals, then measuring the mass uptake regularly and subtracting the mass uptake on a blank vial to correct for iodine adsorbed on the vial walls (Strachan et al., 2010). This experiment was performed to assess the maximum iodine uptake. After 20 days, the iodine crystals were removed and the iodine desorption from the chalcogels was measured. Even after sitting in a desiccator for $>20$ days to remove physisorbed and easily removed $I_{2}$, the chalcogel mass remained constant, indicating a high iodine affinity of $\geq 60 \%$ uptake, by mass.

We then tested the chalcogel affinity for iodine at low concentrations ( $\sim 4 \mathrm{ppm}$, by volume) in air to simulate a dynamic environment more aligned to that of the real off-gas processing facility. In these experiments, $1-5 \mathrm{~mL}$ of chalcogel sorbent was packed into a $10 \mathrm{~mL}$ pipette and air containing $4.2 \mathrm{ppm}$ $\mathrm{I}_{2}(\mathrm{~g})$ was passed through the sorbent column and into a $0.1 \mathrm{M} \mathrm{NaOH}$ scrubbing solution. The scrubber solutions were analyzed for dissolved $\mathrm{I}_{2}$ with ICP-MS. See Figure 4 for a schematic of the experimental apparatus.

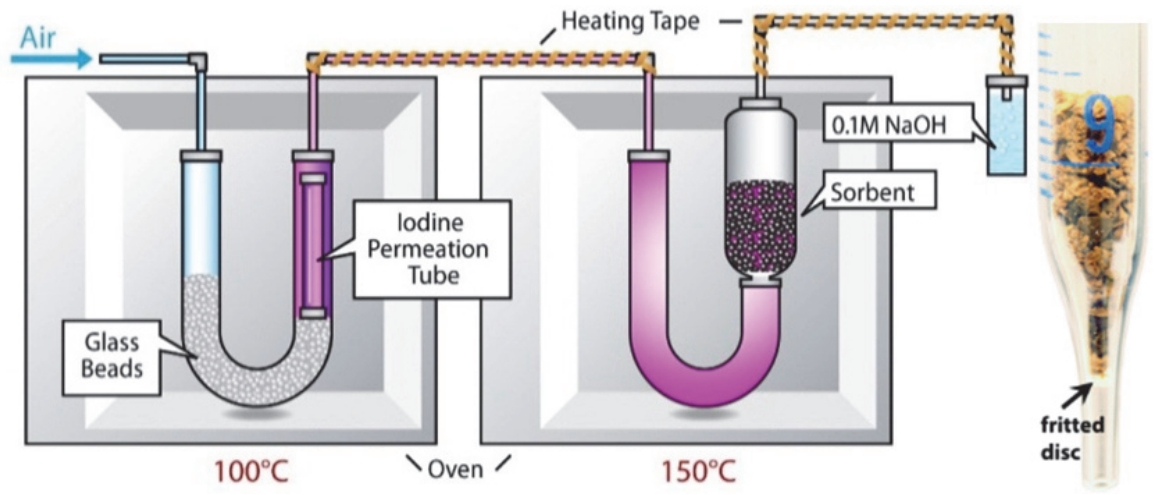

Figure 4. Schematic diagram of the experimental setup for iodine uptake test in breathing air containing $\mathrm{I}_{2}(\mathrm{~g})$ at $4.2 \mathrm{ppm}$ (left) and a photograph of a Pt-Ge-S chalcogel in the tip of the pipette used as the column prior to an experiment (right) (Strachan et al., 2011).

The results from this study showed that chalcogels readily adsorbed iodine at low concentrations from flowing air (Figure 5). Only the Sn-S chalcogel had a capture efficiency greater than that required to meet the Environmental Protection Agency (EPA) guideline of $\geq 99.4 \%$ (or a decontamination factor, DF, $\geq 167$ ) for the duration of the experiment (40 CFR 190, 2012). We also tested $\sim 1 \mathrm{~mL}$ of a Sn-S xerogel in this apparatus that had a specific surface area of $0.14 \mathrm{~m}^{2} / \mathrm{g},>4$ orders of magnitude lower than the 
compositionally equivalent aerogel $\left(456 \mathrm{~m}^{2} / \mathrm{g}\right)$. We did not expect to observe a noticeable adsorption of iodine with the xerogels unless there was a chemical affinity. Even though the capture efficiency of the xerogel was significantly reduced from that of the aerogel, our results showed indirect evidence that these materials have a high affinity for $\mathrm{I}_{2}$. For the Mo-Co-Ni-S chalcogel, iodine breakthrough occurred between 4 and 24 hours, evidenced by a near-zero capture efficiency, i.e., all of the iodine released by the permeation tube was observed by the scrubbing solution.
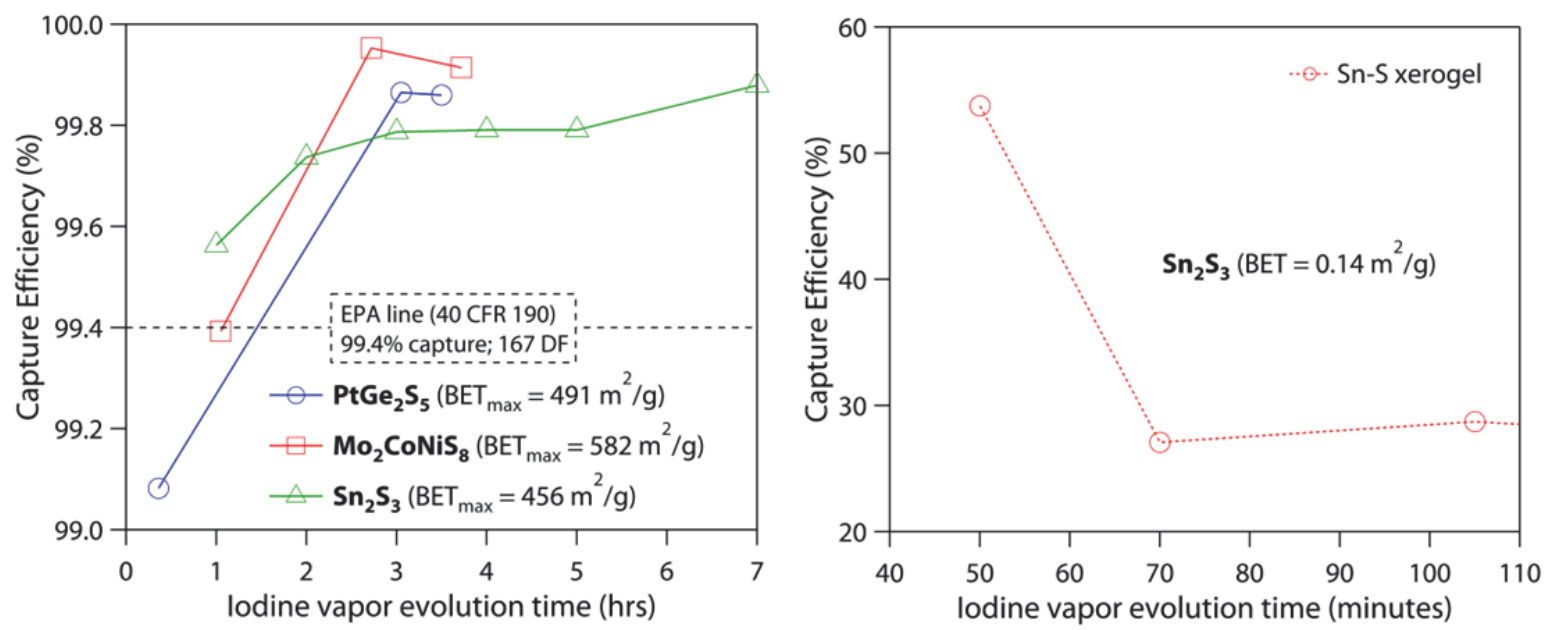

Figure 5. Gaseous iodine adsorption potential of various chalcogel chemistries. 


\section{IMMOBILIZATION POTENTIAL}

Following iodine removal from air, the iodine in the chalcogels needs to be immobilized. One of the reasons for the use of chalcogels is that some can be made into a chalcogenide glass, depending on the chemistry. Chalcogenide glasses have a very high solubility for $I_{2}$ and have the potential for high chemical durability (Heo and Mackenzie, 1989; Wang et al., 2001; Krasteva et al., 1997b; Krasteva et al., 1997a; Seddon and Hemingway, 1991, 1993; Heo et al., 1987; Lin and Ho; Maneglier-Lacordaire et al., 1975; Turyanitsa et al., 1974). From a glass formation standpoint, the most promising chalcogel chemistries are Sn-S or Sn-Se formulations that include Ge or Sb. Since Zn-Sn-S chalcogels tend to change from an amorphous aerogel to a crystalline material when heated (Oh et al., 2011), we suspect this to be the case for the Sn-S chalcogels. Therefore, this system probably requires a glass-forming additive in order to obtain a glassy product after heating, e.g., Ge (Ruffolo and Boolchand, 1985) (Figure 6). Glass formation has been demonstrated in the Sb-Sn-S system with iodine (Turyanitsa et al., 1974). Thus, our focus is on these two systems - Sn-S with a Ge additive and Sb-Sn-S. Several techniques will be evaluated for consolidating both the as-made and iodine-sorbed chalcogels. These include melting, hot pressing, and spark plasma sintering.
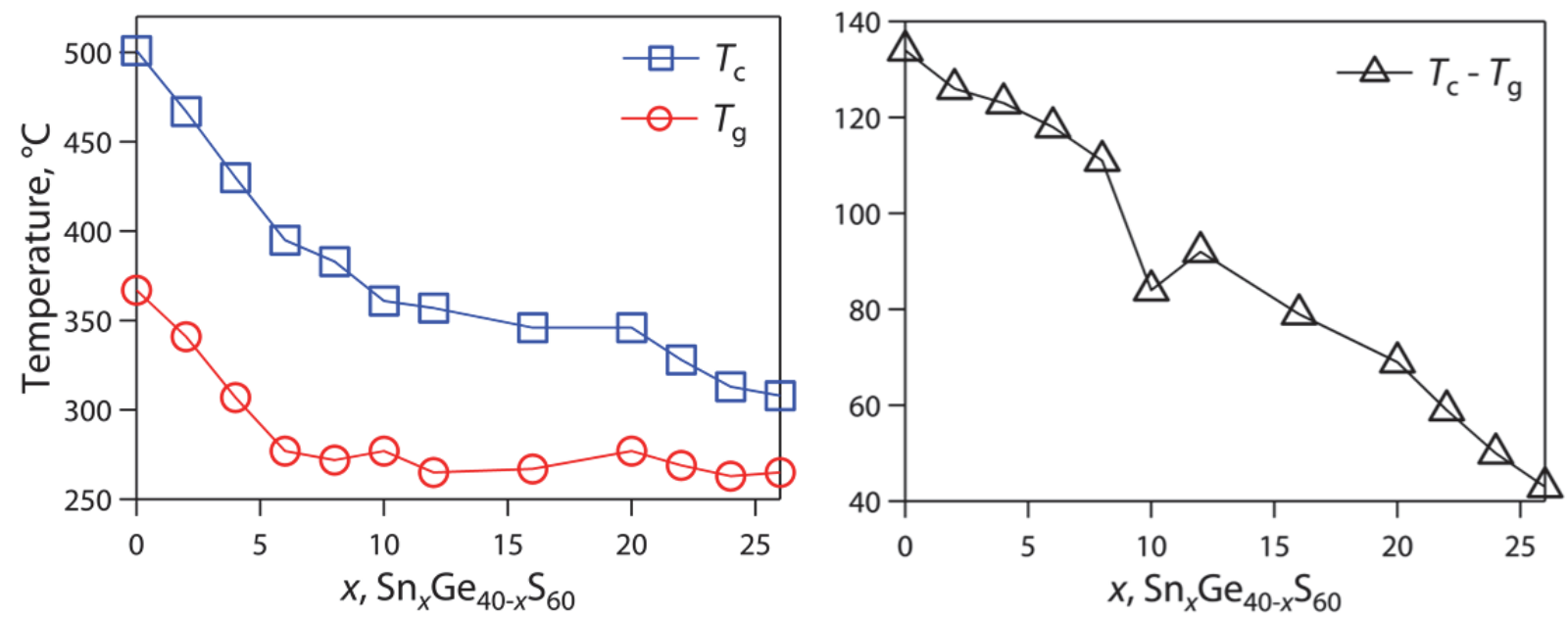

Figure 6. Glass formation tendency in Sn-Ge-S chalcogenide glasses (Ruffolo and Boolchand, 1985). 



\section{CONCLUSIONS}

Chalcogels are composed of metal-chalcogen moieties that are interconnected with a linking metal ion. These materials have very high porosity and strong affinity for halide gases, especially the polarizable $\mathrm{I}_{2}$. Therefore, chalcogels have the potential to be a viable material for the removal of iodine from the process off-gases at a nuclear fuel reprocessing plant. Early investigations of these materials found that the more facile metal ion to study was Pt, an unlikely metal to use in a material ultimately destined for disposal as waste. Hence, we began studying the chemistry of chalcogels with the goal of replacing the Pt with lessexpensive interlinking metal ions. A wide range of possible chemistries are reported in the literature for making non-Pt chalcogels. The three primary systems are 1) $\mathrm{Sn}-\mathrm{S}, 2) \mathrm{Sn}-\mathrm{Sb}-\mathrm{S}$, and 3) Mo-S, with a variety of available interlinking metals. Some of these materials are easier to fabricate than others based on the following factors:

1) Some of the chalcogel precursors are commercially available (e.g., $\mathrm{K}_{2} \mathrm{PtCl}_{4}$ ) and some have to be fabricated in the laboratory (e.g., $\mathrm{Na}_{4} \mathrm{Sn}_{2} \mathrm{~S}_{6}-14 \mathrm{H}_{2} \mathrm{O}$ ).

2) Some of the chalcogel precursors and salts that are used to make the precursors are more expensive than others, i.e., the Pt-based salts are very expensive compared to $\mathrm{Na}_{2} \mathrm{~S}-9 \mathrm{H}_{2} \mathrm{O}$ that is used to make the Na-Sn-S precursor salts $\left(\mathrm{Na}_{4} \mathrm{Sn}_{2} \mathrm{~S}_{6}-14 \mathrm{H}_{2} \mathrm{O}\right.$ and $\left.\mathrm{Na}_{4} \mathrm{SnS}_{4}-14 \mathrm{H}_{2} \mathrm{O}\right)$.

3) Some of the chalcogel precursors are easier than others to fabrication in the laboratory, e.g., (TMA) ${ }_{4} \mathrm{Ge}_{4} \mathrm{~S}_{10}$ can be made in 2 days whereas others take several days and can yield mixed/unpure salts $\left(\mathrm{Na}_{4} \mathrm{Sn}_{2} \mathrm{~S}_{6}-14 \mathrm{H}_{2} \mathrm{O}\right.$ and $\left.\mathrm{Na}_{4} \mathrm{SnS}_{4}-14 \mathrm{H}_{2} \mathrm{O}\right)$.

4) Some chalcogels require more time than others to undergo gelation to create a semi-rigid gel e.g., 2-4 days for $(\mathrm{Sn}, \mathrm{Ge})-\mathrm{Pt}-(\mathrm{S}, \mathrm{Se})$ chalcogels and 4+ weeks for Sn-S chalcogels.

These chalcogels have a wide range of specific surface areas, adsorption potentials, and susceptibilities to oxidation. The most promising chemistries from a glass-formation standpoint are the Ge-Sn-S and SbSn-S systems, both of which are to be studied in more detail in the future. 



\section{ACKNOWLEDGEMENTS}

The authors would like to thank the U.S. Department of Energy, Office of Nuclear Energy for their support of this work under Contract Number DE-AC05-76RL01830. We also thank John Vienna, John McCloy, and Loni Peurrung for helpful review of this document, Robert Jubin (Oak Ridge National Laboratory), and James Bresee (DOE Office of Nuclear Energy) and Terry Todd (Idaho National Laboratory) for project oversight. 



\section{REFERENCES}

40 CFR 190. 2012. Environmental radiation protection requirements for normal operations of activities in the uranium fuel cycle. Environmental Protection Agency, Washington, D.C.

Ahari, H, A Garcia, S Kirkby, GA Ozin, D Young, and AJ Lough. 1998. "Self-assembling iron and manganese metal-germanium-selenide frameworks: [ $\left.\mathrm{NMe}_{4}\right]_{2} \mathrm{MGe}_{4} \mathrm{Se}_{10}$, where $\mathrm{M}=\mathrm{Fe}$ or Mn." Journal of the Chemical Society, Dalton Transactions 2023:2023-28.

Bag, S, AF Gaudette, ME Bussell, and MG Kanatzidis. 2009. "Spongy chalcogels of non-platinum metals act as effective hydrodesulfurization catalysts." Nature Chemistry 1(3):217-24.

Bag, S and MG Kanatzidis. 2010. "Chalcogels: Porous Metal-Chalcogenide Networks from Main-Group Metal Ions. Effect of Surface Polarizability on Selectivity in Gas Separation." Journal of the American Chemical Society 132(42):14951-59.

Bag, S, PN Trikalitis, PJ Chupas, GS Armatas, and MG Kanatzidis. 2007. "Porous semiconducting gels and aerogels from chalcogenide clusters." Science 317(5837):490-93.

Bowes, CL, WU Huynh, SJ Kirkby, A Malek, GA Ozin, S Petrov, M Twardowski, and D Young. 1996. "Dimetal linked open frameworks: $\left[\left(\mathrm{CH}_{3}\right)_{4} \mathrm{~N}\right]_{2}\left(\mathrm{Ag}_{2}, \mathrm{Cu}_{2}\right) \mathrm{Ge}_{4} \mathrm{~S}_{10}$." Chemistry of Materials 8:2147-52.

Coucouvanis, D, M Kanatzidis, E Simhon, and NC Baenziger. 1982. "Synthesis, molecular structure, and reactions of bis(tetraphenylphosphonium) hexakis(.mu.-thiophenolato)-tetrachlorotetraferrate(II), $\left(\mathrm{Ph}_{4} \mathrm{P}\right)_{2}\left[\mathrm{Fe}_{4}(\mathrm{SPh})_{6} \mathrm{Cl}_{4}\right]$. Its reactions with dibenzyl trisulfide and the synthesis of the $\left[\mathrm{Fe}_{4} \mathrm{~S}_{4} \mathrm{Cl}_{4}\right]^{2-}$ and $\left[\mathrm{Fe}_{4} \mathrm{~S}_{4}(\mathrm{Cl})_{2}\left(\mathrm{SC}_{6} \mathrm{H}_{5}\right)_{2}\right]^{2-}$ "cubane"-type clusters." Journal of the American Chemical Society 104(7):187482.

Eisenmann, B and J Hansa. 1993. "Crystal structure of tetrapotassium hexaselenodistannate, $\mathrm{K}_{4} \mathrm{Sn}_{2} \mathrm{Se}_{6} . "$ Zeitschrift fur Kristallographie 203(2):299-300.

Eisenmann, B and R Zagler. 1989. "Selenoantimonates(V): preparation and crystal structure of $\mathrm{Na}_{3} \mathrm{SbSe}_{4}$, $\mathrm{K}_{3} \mathrm{SbSe}_{4}$, and $\left[\mathrm{Ba}(\mathrm{en})_{4}\right]_{2}\left[\mathrm{Ba}(\mathrm{en})_{3}\right]\left(\mathrm{SbSe}_{4}\right)_{2} . "$ Zeitschrift fuer Naturforschung, B: Chemical Sciences 44(3):249-56.

Heo, J and JD Mackenzie. 1989. "Chalcohalide glasses: I. Synthesis and properties of Ge-S-Br and Ge-SI glasses." Journal of Non-Crystalline Solids 111(1):29-35.

Heo, J, JS Sanghera, H Nasu, and JD Mackenzie. 1987. "The structure and properties of infrared transmitting chalcohalide glasses." Materials Science Forum 19-20(1):55-62.

Kalebaila, KK, DG Georgiev, and SL Brock. 2006. "Synthesis and characterization of germanium sulfide aerogels." Journal of Non-Crystalline Solids 352(3):232-40.

Kanatzidis, MG and S Bag. 2008. "Semiconducting aerogels from chalcogenido clusters with broad applications." USA Application No. US 2008/0241050 A1. 
Klepp, KO. 1992. "Na $\mathrm{SnSe}_{4}$ and $\mathrm{K}_{4} \mathrm{SnSe}_{4}$, Two new selenostannates with discrete anions." Zeitschrift fuer Naturforschung B: Chemical Sciences 47(3):411-17.

Krasteva, V, D Hensley, and GH Sigel. 1997a. "The effect of compositional variations on the properties of rare-earth doped Ge-S-I chalcohalide glasses." Journal of Non-Crystalline Solids 222:235-42.

Krasteva, V, D Machewirth, and GH Sigel. 1997b. "Pr ${ }^{3+}$-doped Ge-S-I glasses as candidate materials for $1.3 \mu \mathrm{m}$ optical fiber amplifiers." Journal of Non-Crystalline Solids 213-214:304-10.

Krebs, VB, S Pohl, and W Schiwy. 1972. "Darstellung und Struktur von $\mathrm{Na}_{4} \mathrm{Ge}_{2} \mathrm{~S}_{6} \cdot 14 \mathrm{H}_{2} \mathrm{O}$ und $\mathrm{Na}_{4} \mathrm{Sn}_{2} \mathrm{~S}_{6} \cdot 14 \mathrm{H}_{2} \mathrm{O}$ " Zeitschrift fuer Anorganische und Allgemeine Chemie 393:241-52.

Lin, FC and S-M Ho. 1963. "Chemical durability of arsenic-sulfur-iodine glasses." Journal of the American Ceramic Society 46(1):24-28.

Maneglier-Lacordaire, S, J Rivet, and J Flahaut. 1975. "Le systeme ternaire germanium-soufre-iode, construction du diagramme de phase et etude des verres." Annales de chimie et de physique 10(6):291-99.

McDonald, JW, GD Friesen, LD Rosenhein, and WE Newton. 1983. "Syntheses and characterization of ammonium and tetraalkylammonium thiomolybdates and thiotungstates." Inorganica Chimica Acta 72:205-10.

Mohanan, JL, IU Arachchige, and SL Brock. 2005. "Porous semiconductor chalcogenide aerogels." Science 307:397-400.

Oh, Y, S Bag, CD Malliakas, and MG Kanatzidis. 2011. "Selective surfaces: high-surface-area zinc tin sulfide chalcogels." Chemistry of Materials 23(9):2447-56.

Polychronopoulou, K, C Malliakas, J He, and M Kanatzidis. 2012. "Selective Surfaces: Quaternary $\mathrm{Co}(\mathrm{Ni}) \mathrm{MoS}-$ based Chalcogels with Divalent $\left(\mathrm{Pb}^{2+}, \mathrm{Cd}^{2+}, \mathrm{Pd}^{2+}\right)$ and Trivalent $\left(\mathrm{Cr}^{3+}, \mathrm{Bi}^{3+}\right)$ Metals for Gas Separation." Chemistry of Materials:in press.

Riley, BJ, J Chun, JV Ryan, J Matyáš, XS Li, DW Matson, SK Sundaram, DM Strachan, and JD Vienna. 2011. "Chalcogen-based aerogels as a multifunctional platform for remediation of radioactive iodine." RSC Advances 1:1704-15.

Ruffolo, D and P Boolchand. 1985. "Origin of Glass Formation." Physical Review Letters 55(2):242-45.

Ryan, J, E Buck, J Chun, J Crum, B Riley, D Strachan, S Sundaram, L Turo, and J Vienna. 2009. Alternate Waste Forms: Aqueous Processing. Report No. AFCI-WAST-PMO-MI-DV-2009-000360, PNNL, Richland, WA.

Schiwy, VW, S Pohl, and B Krebs. 1973. "Darstellung und Struktur von $\mathrm{Na}_{4} \mathrm{SnS}_{4} \cdot 14 \mathrm{H}_{2} \mathrm{O}$." Zeitschrift fuer Anorganische und Allgemeine Chemie 402:77-86.

Seddon, AB and MA Hemingway. 1993. "Thermal characterization of infrared-transmitting Ge-S-I glasses." Journal of Non-Crystalline Solids 161:323-26. 
Seddon, AB and MA Hemingway. 1991. "Thermal properties of chalcogenide-halide glasses in the system: Ge-S-I." Journal of Thermal Analysis and Calorimetry 37(9):2189-203.

Shafaei-Fallah, M, R Alexander, AP Katsoulidis, J He, CD Malliakas, and MG Kanatzidis. 2011. "Extraordinary Selectivity of $\mathrm{CoMo}_{3} \mathrm{~S}_{13}$ Chalcogel for $\mathrm{C}_{2} \mathrm{H}_{6}$ and $\mathrm{CO}_{2}$ Adsorption." Advanced Materials 23(42):4857-60.

Strachan, D, J Chun, CH Henager Jr., J Matyas, BJ Riley, JV Ryan, and PK Thallapally. 2010. Summary Report for the Development of Materials for Volatile Radionuclides. Report No. PNNL-20007, Pacific Northwest National Laboratory, Richland, WA.

Strachan, DM, WD Bennett, CC Bonham, J Chun, W Lepry, J Matyas, BJ Riley, JV Ryan, V Shutthanandan, and PK Thallapally. 2011. Summary Report on Volatile Radionuclides Research at PNNL. Report No. FCRD-SWF-2011-000378, Pacific Northwest National Laboratory, Richland, WA.

Tsamourtzi, K, J-H Song, T Bakas, AJ Freeman, PN Trikalitis, and MG Kanatzidis. 2008.

"Straightforward Route to the Adamantane Clusters $\left[\mathrm{Sn}_{4} \mathrm{Q}_{10}\right]^{4-}$ (Q) S, Se, Te) and Use in the Assembly of Open-Framework Chalcogenides $\left(\mathrm{Me}_{4} \mathrm{~N}\right)_{2} \mathrm{M}\left[\mathrm{Sn}_{4} \mathrm{Se}_{10}\right]\left(\mathrm{M}=\mathrm{Mn}^{\mathrm{II}}, \mathrm{Fe}^{\mathrm{II}}, \mathrm{Co}^{\mathrm{II}}, \mathrm{Zn}^{\mathrm{II}}\right)$ Including the First Telluride Member $\left(\mathrm{Me}_{4} \mathrm{~N}\right)_{2} \mathrm{Mn}\left[\mathrm{Ge}_{4} \mathrm{Te}_{10}\right]$." Inorganic Chemistry 47(24):11920-29.

Turyanitsa, ID, IM Migolinets, BM Koperles, and IF Kopinets. 1974. "Investigation of glasses in the systems Sn-Sb-S-I and Pb-Sb-S-I." Neorganicheskie Materialy 10(8):1436-38.

Wang, Y, J Wells, DG Georgiev, P Boolchand, K Jackson, and M M. 2001. "Sharp rigid to floppy phase transition induced by dangling ends in a network glass." Physical Review Letters 87(18):185503-1.

Yuhas, BD, C Prasittichai, JT Hupp, and MG Kanatzidis. 2011a. "Enhanced Electrocatalytic Reduction of $\mathrm{CO}_{2}$ with Ternary Ni-Fe $\mathrm{S}_{4}$ and $\mathrm{Co}-\mathrm{Fe}_{4} \mathrm{~S}_{4}$-Based Biomimetic Chalcogels." Journal of the American Chemical Society 133(40):15854-57.

Yuhas, BD, AL Smeigh, APS Samuel, Y Shim, S Bag, AP Douvalis, MR Wasielewski, and MG Kanatzidis. 2011b. "Biomimetic Multifunctional Porous Chalcogels as Solar Fuel Catalysts." Journal of the American Chemical Society 133(19):7252-55. 



\section{APPENDIX A: \\ COMPILATION OF SELECTED CHALCOGEL DATA FROM LITERATURE}




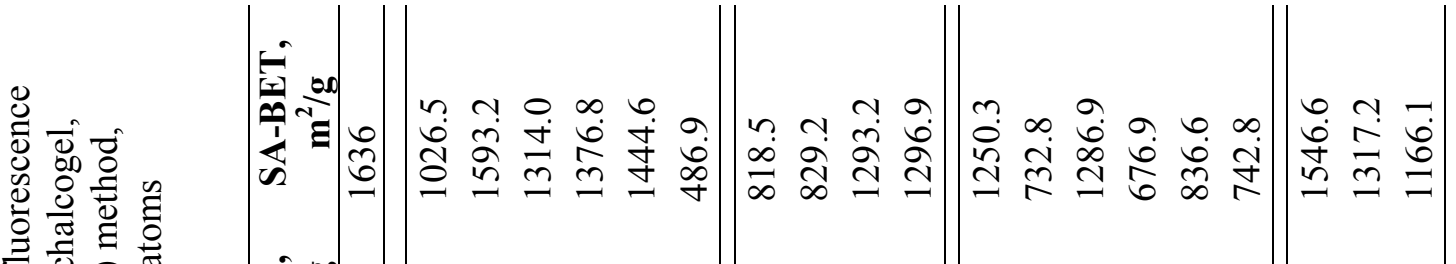

在至

స

$x \notin$

తิ)

$\because \stackrel{\circ}{\oplus \circ}$

品声

ब国

들 至

$3 \Xi \dot{\overline{0}}:$

on $\vec{\pi}$

ज्ञ छ

๑.$\Xi$

تี

.․․잉

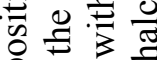

욜요

of

दु के

远藏

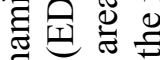

है ठ

D雨

I 0 का

$\because$ 造

के

300

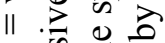

3 空

․ㅡㄴ.

ฮี :

긍 क्ति

* छ

* $\dot{0} \overrightarrow{\mathbb{D}}$

क्ष 0.00

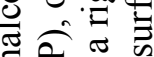

U

ธี ซิ

ह छ के

늘

의

멍

害官

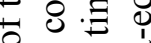

긍휴

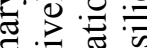

论

क $\Xi \cong . \simeq$

을ํ

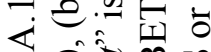

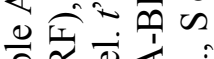

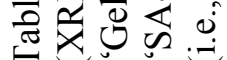

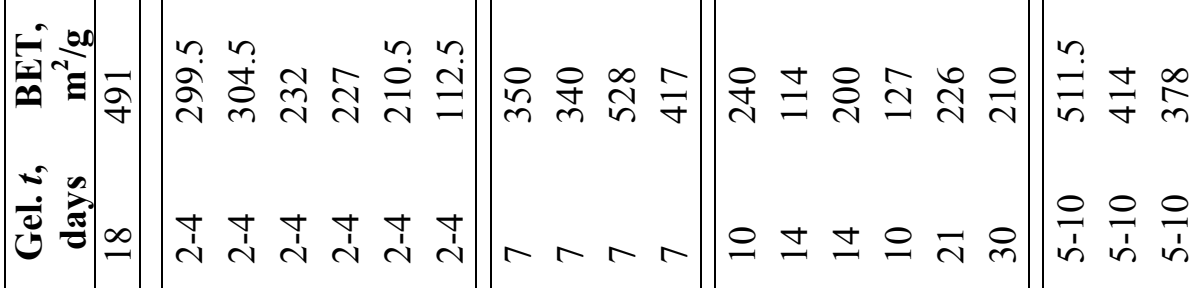

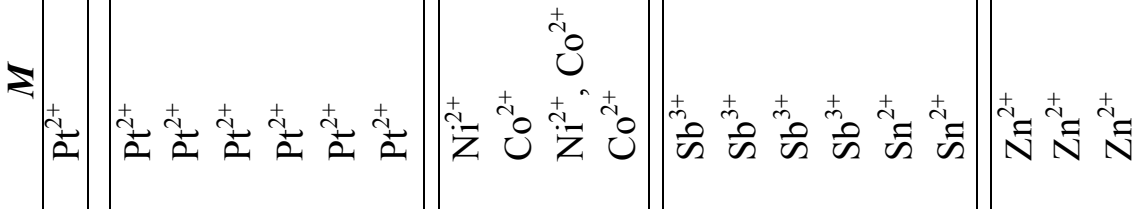

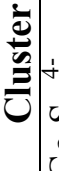

$i$
0
0
0

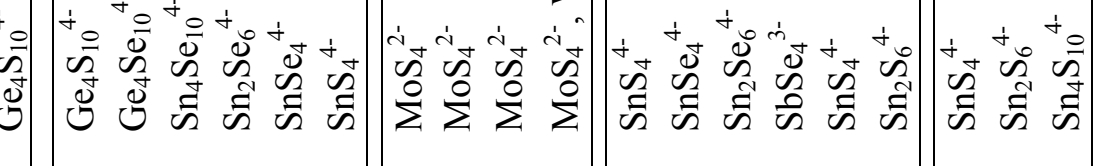

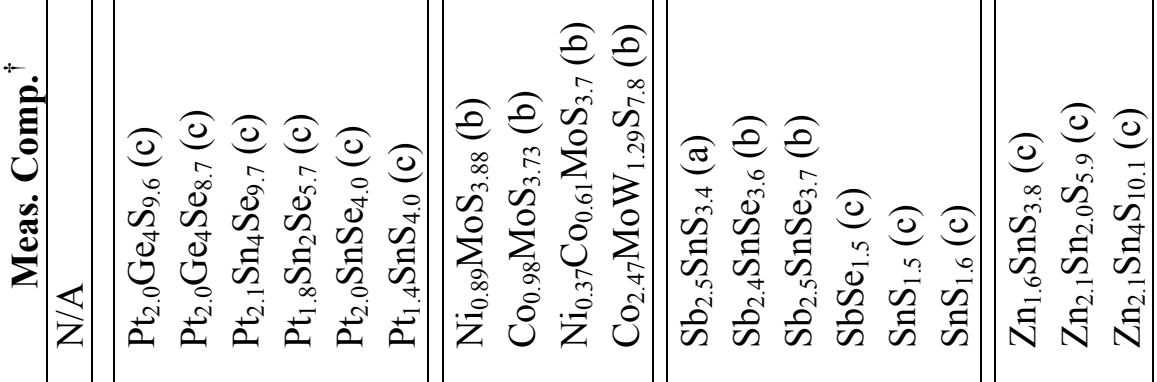

|

*.

:

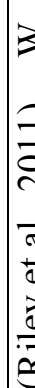

3

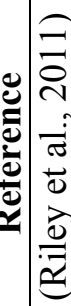

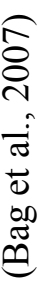

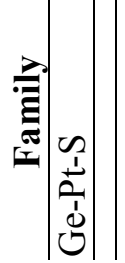

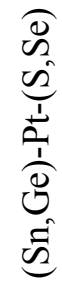

$\sum_{i=1}^{1}$

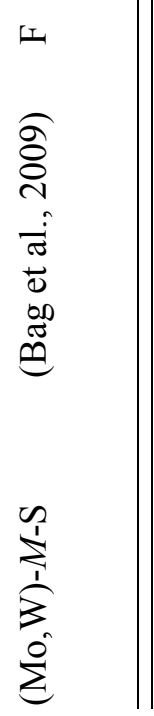

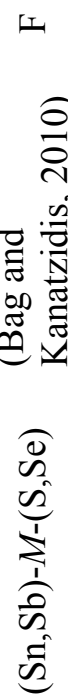

L

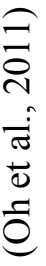

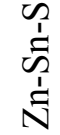




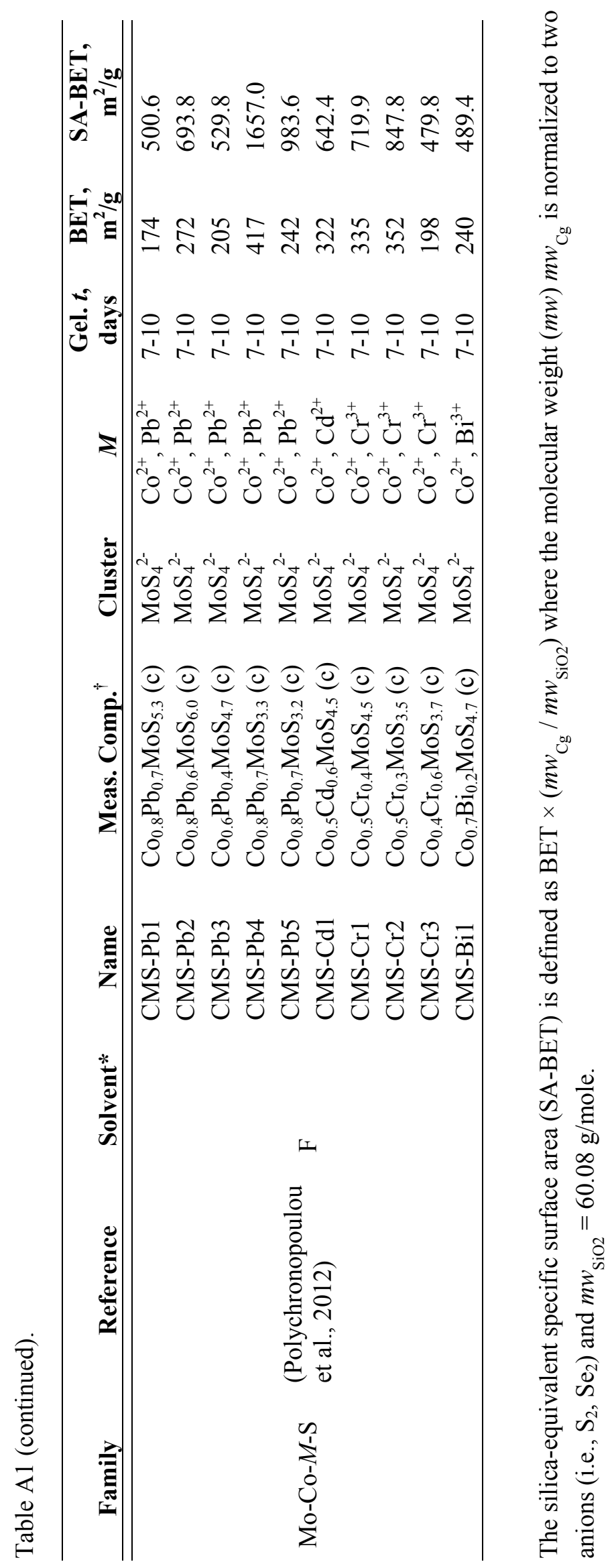

